\title{
Effects of controlled oxidative stress and uncouplers on primary photosynthetic processes in vegetative cells of Antarctic alga Zygnema sp.
}

\author{
Christos Kakkou ${ }^{1}$, Miloš Barták ${ }^{2}$, Josef Hájek $^{2}$, Kateřina Skácelová ${ }^{2}$, \\ Jana Hazdrová ${ }^{2}$ \\ ${ }^{1}$ Faculty of Medicine, Masaryk University, University campus, Kamenice 5, 62500 Brno, \\ Czech Republic \\ ${ }^{2}$ Laboratory of Photosynthetic Processes, Division of Plant Physiology and Anatomy, \\ Department of Experimental Biology, Faculty of Science, Masaryk University, Building \\ A13, Kamenice 5, 62500 Brno, Czech Republic
}

\begin{abstract}
In our study, we present responses of Antarctic strain of filamentous alga Zygnema sp. collected at James Ross Island (Antarctica) to application of variuos uncouplers of primary photosynthetic processes. We exposed the alga to different concentrations of nigericin, 3-(3,4-dichlorophenyl)-1,1-dimethylurea (DCMU), dithiothreitol (DTT), methyl viologen (MV) and hydrogen peroxide $\left(\mathrm{H}_{2} \mathrm{O}_{2}\right)$ in order to test stability of photosystem II, involvement of non-photochemical quenching, and PS II functioning under combination of moderate light with particular uncoupler. Oxidative stress tolerance was tested by the combination of hydrogen peroxide $\left(\mathrm{H}_{2} \mathrm{O}_{2}\right)$ and moderate light. Time courses of $\mathrm{F}_{\mathrm{V}} / \mathrm{F}_{\mathrm{M}}$, $\Phi_{\text {PSII }}, \mathrm{NPQ}$ and $\mathrm{qF}_{0}$ were investigated and particular effects of the above-specified chemicals discussed. Moderate doses of uncouplers allowing partial recovery, and the doses causing full inhibition of PS II were specified.
\end{abstract}

Key words: chlorophyll fluorescence, PS II, alga, fillamentous, photosynthesis blockers

Abbreviations: DCMU - 3-(3,4-dichlorophenyl)-1,1-dimethylurea, DTT - dithiothreitol, $\mathrm{H}_{2} \mathrm{O}_{2}$ - hydrogen peroxide, $\mathrm{MV}$ - methyl viologen, NPQ - non-photochemical quenching

DOI: $10.5817 / \mathrm{CPR} 2016-1-10$

Received February 23, 2016, accepted May 25, 2016.

*Corresponding author: Miloš Barták <mbartak@sci.muni.cz>

Acknowledgements: The authors thank CzechPolar infrastructure (CzechPolar Project I (LM2010009) and II (LM2015078) provided by the Czech Ministry of Education, Youth and Sports). 


\section{Introduction}

Zygnema is a filamentous green alga inhabiting a wide variety of habitats ranging from wet to semiwet terrestrial ecosystems. In Antarctica, Zygnema represents an autotrophic organism abundant in terrestrial freshwater ecosystems, such as streams, ponds and lakes. It is reported mainly from maritime Antarctica, e.g. Signy Island (Hawes 1989), King George Island (Pichrtová et al. 2014).

Photosynthetic apparatus of vegetative cells of Zygnema is characterized by two, star-shaped chloroplasts located in an individual cell. Typically, visible nucleus can be distinguished between the chloroplasts, and a non-extensive sheath, vacuols and pyrenoids, are visible. In pre-akinetes and akinetes, cell anatomy is changed (Fuller 2013).

Polar strains of Zygnema, their ecophysiological characteristics in particular, have been investigated within last two decades with the main emphasis given to resistance to osmotic stress (Vilumbrales et al. 2013, Herburger et al. 2015), UV-B treatment (Holzinger et al. 2009), and different proportion of UV-B to PAR irradiation (Pichrtová et al. 2013). These studies focused selected parts of photosynthetic performace of Zygnema, using chlorophyll fluorescence approach. Detailed analysis of photosynthetic processes in photosystem II in Zygnema, however, has not yet been done. Specifically, application of inhibitors of PS II and/or linear photosynthetic electron transport is missing. This study focused on the response of PS II to several uncouplers of primary photosynthetic processes, especially dose and treatment duration effects (see below).

Nigericine, a protonophore, is known as an effective uncoupler of photosynthetic electron flow (e.g. Nishio et Whitmarsh 1993). In the presence of nigericin, the $\mathrm{pH}$ gradient across thylakoid membranes is eliminated (see e.g. Myiake et Yokota (2001) without significantly affecting the potential gradient, thereby maintaining ATP synthesis, photosystem II is affected in such a way that $\mathrm{pH}$-dependent components of non-photochemical quenching ( $\mathrm{qE}$ in particular, see e.g. Vavilin et al. 1998) are partly or fully supressed. Therefore, addition of nigericine is used to study involvement on $\mathrm{pH}$-independent mechanisms involved into photoprotection of chloroplastic photosynthetic apparatus (see e.g. Dall'Osto et al. 2005). In chlorophyll fluorescence studies, nigericin is reported having either no effect (isolated chloroplasts - Bukhov et al. 2004) on fast chlorophyll fluorescence transients (OJIPs) or the effects causing an increase in chlorophyll fluorescence signal during O-J phase in diatoms (Antal et al. 2011). In this study, signal coming prevalently from PS II antennae was reported nigericin-affected and causing partial inhibition of PS II. Effects of nigericine on slow chlorophyll fluorescence curves and the parameters derived from them is much less studied in algae (see e.g. Kaňa et al. 2012 for cryptophytes). However, the approach has been used to study PS II and PS I cyclic electron flows as affected by photoinhibitory treatment in presence of nigericine (Joliot et Johnson 2011). The study reports that nigericine inhibits NPQ, however, does not result in any change in $\Phi_{\mathrm{PSII}}$.

Dithiothreitol (DTT), an inhibitor of violaxanthin de-epoxidase, is generally used in the studies focused on sensitivity of experimental species to photoinhibition, capacity of transthylakoidal delta $\mathrm{pH}$ dependent photoprotective mechanisms in particular (see e.g. Essemine et al. 2012). Typically, non-photochemical quenching (NPQ) is responsible of dissipation of excessive absorbed light energy as heat to protect thylakoidal photosynthetic apparatus against photodamage. In photoinhibitory studies, major component of NPQ is dependent of the transthylakoid $\mathrm{pH}$ gradient and is modulated by $\mathrm{pH}-d e p e n d e n t$ con- 
version of violaxanthin to zeaxanthin. In such studies, DTT inhibits zeaxanthin formation.

Methyl viologen (MV) is a very effective electron acceptor that competes strongly with ferredoxin for electrons from the FeS clusters of photosystem I (PS I). Therefore, MV suppresses cyclic electron transfer around PS I (Cornic et al. 2000). In fluorometric studies of higher plants devoted to functioning of their photochemical photosynthetic processes, MV effects on OJIPs (Schansker et al. 2005) and slow chlorophyll kinetics (Iriel et al. 2014) were studied. Recent studies (e.g. Fan et al. 2009) report negative effects on PS II, effective quantum yield in particular. In algae, however, MV effects on PS II / PS I are much less studied.

By blocking the electron acceptor side of PS II, DCMU causes a fluorescence rise to $F_{M}$. In some studies, DCMU-induced $F_{M}$ is used instead of illumination-induced $F_{M}$ (Simis et al. 2012) in order to reduce number of repetitive chlorophyll fluorescence measurements using saturation pulse method. The method can be applied even in the field as showed by Kolmakov et al.

\section{Material and Methods}

\section{Cultivation of experimental alga}

We used Zygnema sp. (strain EEL201, Collection of Extreme Environment Life Laboratory, Masaryk University, Brno, Czech Republic, see Fig. 1, 2). Originally, the species was collected at James Ross Island (Antarctica) from a long-term research plot located close to Mendel station $\left(63^{\circ} 48^{\prime} 03^{\prime \prime} \mathrm{S}, 57^{\circ} 52^{\prime} 50^{\prime \prime} \mathrm{W}\right)$. The samples were collected into $30 \mathrm{ml}$ plastic tubes, then stored in a refrigerator at $5^{\circ} \mathrm{C}$. Samples were then transported to a laboratory
(2008) for $F_{V} / F_{M}$ calculation and consequent estimation of freshwater algae productivity. In studies focused on primary photosynthetic processes exploiting chlorophyll fluorescence approach, DCMU is used to block photosynthetic linear electron transport chain to characterize properties of photosystem II. Volgusheva et al. (2007) used DCMU in chlorophyll fluorescence decay measurements. Recently, Vredenberg (2015) applied DCMU in aqueous suspension of Nannochloropsis to study changes in chlorophyll fluorescence signals $\left(\mathrm{F}_{0}\right.$, and others) and parameters derived from fast chlorophyll fluorescence curves (OJIPs).

In this study, we focused on doserelated effects of nigericine, DTT, MV, DCMU and oxidative stress $\left(\mathrm{H}_{2} \mathrm{O}_{2}\right)$ on photosynthetic processes in chloroplastic apparatus of Zygnema. We focused on evaluation of effective (inhibiting) doses of particular above-specified chemicals, as well as those doses allowing recovery from chemical-induced inhibition of primary photochemical processes of photosynthesis.

to Brno in a portable box maintaining low temperature of $7^{\circ} \mathrm{C}$. In a laboratory, $Z y g$ nema sp. was inoculated to a BBM agar and cultivated on Petri dishes for 8 weeks at $22^{\circ} \mathrm{C}$ and $60 \mu \mathrm{mol} \mathrm{m} \mathrm{m}^{-2} \mathrm{~s}^{-1}$ PAR. When Zygnema sp. developes substantial biomass, it was inserted into a liquid medium and cultivated in $100 \mathrm{ml}$ glass flasks. After 3 weeks of cultivation in liquid medium, Zygnema sp. was used for experiments. 


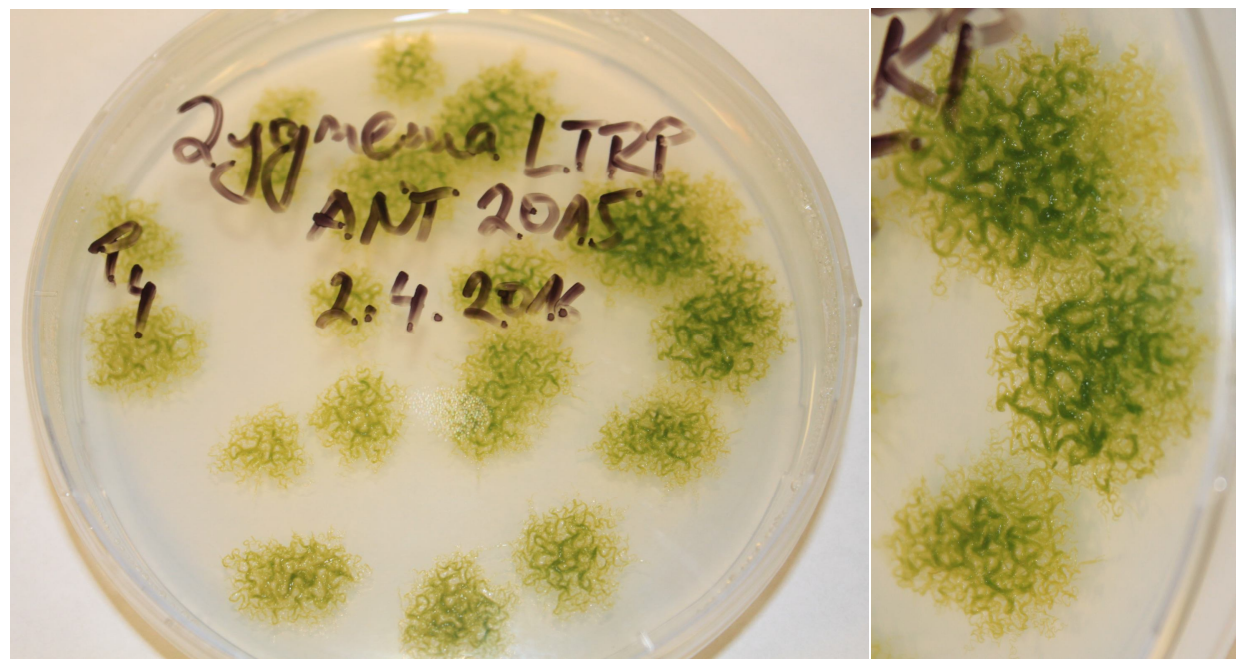

Fig. 1. Zygnema sp. (EEL201 strain) cultured on BBM agars forms clusters of filaments resulting in complex 2-D structures. Photo: M. Barták.

\section{Treatment by uncuplers and specific inhibitors}

Extent of inhibition of photosynthetic processes in PS II was evaluated by addition of DCMU, nigericin and $\mathrm{H}_{2} \mathrm{O}_{2}$ into algal culture followed by repeated measurements of chlorophyll fluorescence parameters (see below) lasting for $4 \mathrm{~h}$ after particular uncoupler addition. During the treatment, Zygnema sp. was exposed either to low and high light: 10 and $1000 \mu \mathrm{mol}$ $\mathrm{m}^{-2} \mathrm{~s}^{-1}$ of photosynthetically active radiation (PAR) so that the negative effects of interacting light intensity on functioning of PS II could be evaluated.

\section{Chlorophyll fluorescence measuremets}

Fluorescence induction transients (slow Kautsky kinetics) of the intact algal filaments were measured in holes of a microbiological plate after 5 min dark adaptation at $5^{\circ} \mathrm{C}$. The fluorescence kinetics supplemented by quenching analysis were recorded by a HFC-010 fluorometer (Photon Systems Instruments, Czech Republic) using a chlorophyll fluorescence imaging approach as described earlier (see e.g. Conti et al. 2014). To assess the effects of particular uncouplers and light treatment, the following chlorophyll parameters were measured and evaluated: potential yield of photochemical photosynthetic processes in PS II $\left(\mathrm{F}_{\mathrm{V}} / \mathrm{F}_{\mathrm{M}}\right)$, effective yield of photochemical photosynthetic processes in PS II $\left(\Phi_{\mathrm{PSII}}\right)$, non-photochemical quenching of chlorophyll fluorescence (NPQ), and quenching of background chlorophyll fluorescence $\mathrm{qF}_{0}\left(\mathrm{qF}_{0}=\left(\mathrm{F}_{0}-\mathrm{F}_{0}{ }^{\prime}\right) / \mathrm{F}_{0}\right.$. Time response curves of the chlorophyll fluorescence parameters were constructed and dose-response effects on the parameters statistically evaluated. 


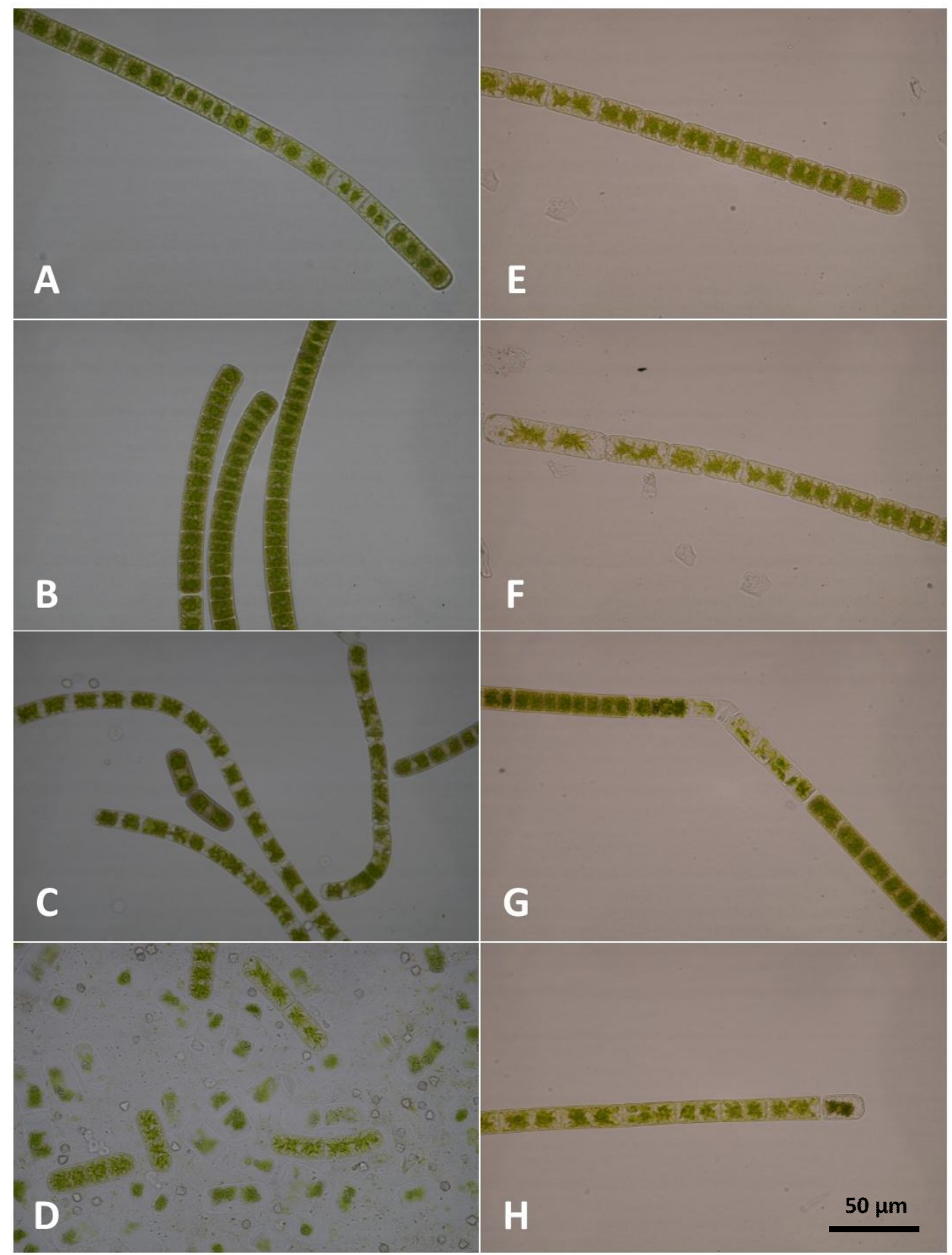

Fig. 2. Individual filaments of Zygnema sp. (EEL201 strain) when cultured on a BBM medium. Photo: K. Skácelová. 


\section{Results and Discussion}

\section{DCMU effects}

DCMU is a typical PS II inhibitor which prevent the electron transfer from $Q_{\mathrm{A}}$ to a secondary acceptor $Q_{\mathrm{B}}$. In fact, DCMU displaces $Q_{\mathrm{B}}$ from its binding site at PS II (Lavergne 1982), application of DCMU leads to a blockage of linear electron transport chain (see e.g. Ducruet et al. 1984). It is demonstrated as a rapid increase of chlorophyll fluorescence from $\mathrm{O}$ to $\mathrm{P}$ level (see Fig. 3) since absorbed light energy can not be delivered from PS II to plastoquinone pool. Our results suggest that after DCMU application, some limited number of PS II centres are still capable to transfer absorbed light energy since $\mathrm{P}$ level of chlorophyll fluorescence is reached at comparable time as control and there is some intermediate phase (see an arrow in Fig. 3) indicating that not all PSIIs are blocked by DCMU. Moreover, complementary area be- tween the fluorescence transient ( $\mathrm{O}$ to $\mathrm{P}$ ) measured in the presence of DCMU and the delimiting lines passing through $\mathrm{O}$ (vertical) and $\mathrm{P}$ (horizontal) is proportional to the share of reduced $Q_{\mathrm{A}}$ molecules (for more information on DCMU effects on fast chlorophyll fluorescence kinetics - see Roháček et al. 2008). Therefore, some strongly limited but still detectable extent of primary photosynthetic processes can be expected. This idea might be supported by slow chlorophyll fluorescence kinetics (see Fig. 4) which shows $F_{M}$ ' peak after saturation pulse and, therefore, effective quantum yield of PS II value about 0.06 immediately (5 min.) after DCMU addition. With prolonged time of exposition to DCMU, effective quantum yield of PS II declined to almost zero (after $120 \mathrm{~min}$.).

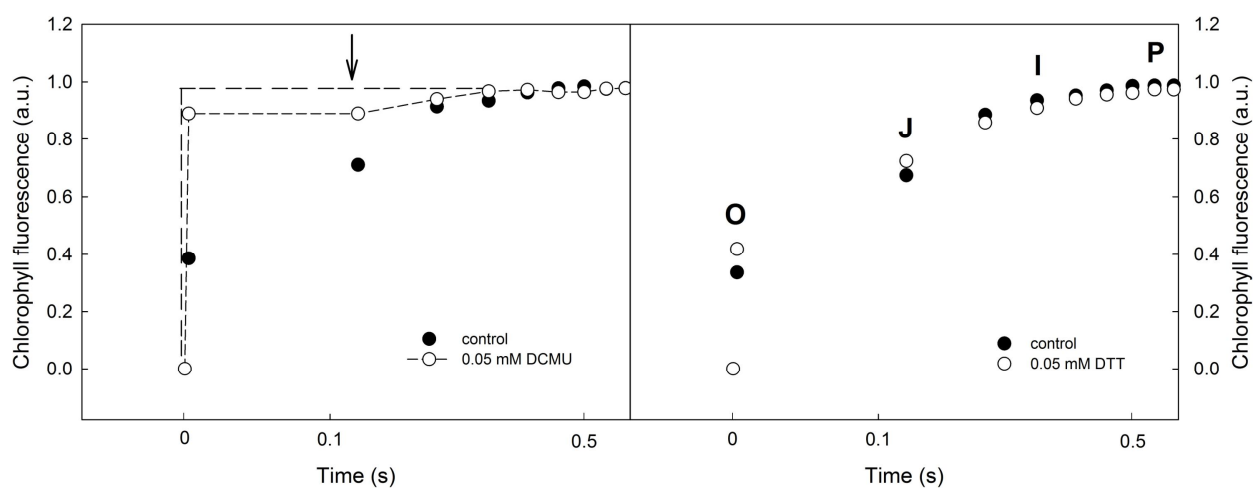

Fig. 3. Fast chlorophyll fluorescence kinetics recorded in the absence (full symbols) and presence (open symbols) of DCMU - left panel. An arrow indicate an intermediate phase between J and I levels of chlorophyll fluorescence in not completely blocked PS II reaction centres. Right panel Effects of DTT on fast chlorophyll fluorescence kinetic (OJIP). 


\section{DTT effects}

Dithiothreitol (DTT) is used in many physiological studies as an inhibitor violaxanthin de-epoxidation and an agens affecting the xanthophyll cycle pigments interconversion negatively. Therefore, the effects on shape and time courses of fast chlorophyll fluorescence transients is studied very rarely. Our results indicate slightly higher values of chlorophyll fluorescence found within the time interval of 0 to $0.2 \mathrm{~s}$ in DTT-treated Zygnema than in control (Fig. 3). Such increase relates to $\mathrm{J}$ and I chlorophyll fluorescence levels that are attributed to energy transfer from LHCs to RCs and a primary acceptor. Similar results were obtained for DTTtreated algal lichen Lobaria pulmonaria by
Fernández-Marín et al. (2010) who reported DTT-induced increase in I and J chlorophyll fluorescence level in dried and subsequently hydrated thalli. Their explanation of the chlorophyll fluorescence increase relates to an integrity and function of the photosynthetic apparatus during desiccation and a potential role of lack zeaxanthin in this process. In our study, we may attribute the increase of chlorophyll fluorescence signal within the range of 0 to $0.2 \mathrm{~s}$ to a combined structural effect of PS II and possible photodamage of PS II due to lack of zeaxanthine. Early stages of photoinhibition and photodamage of PS II are demonstrated by a similar modification of the OJIP transient.

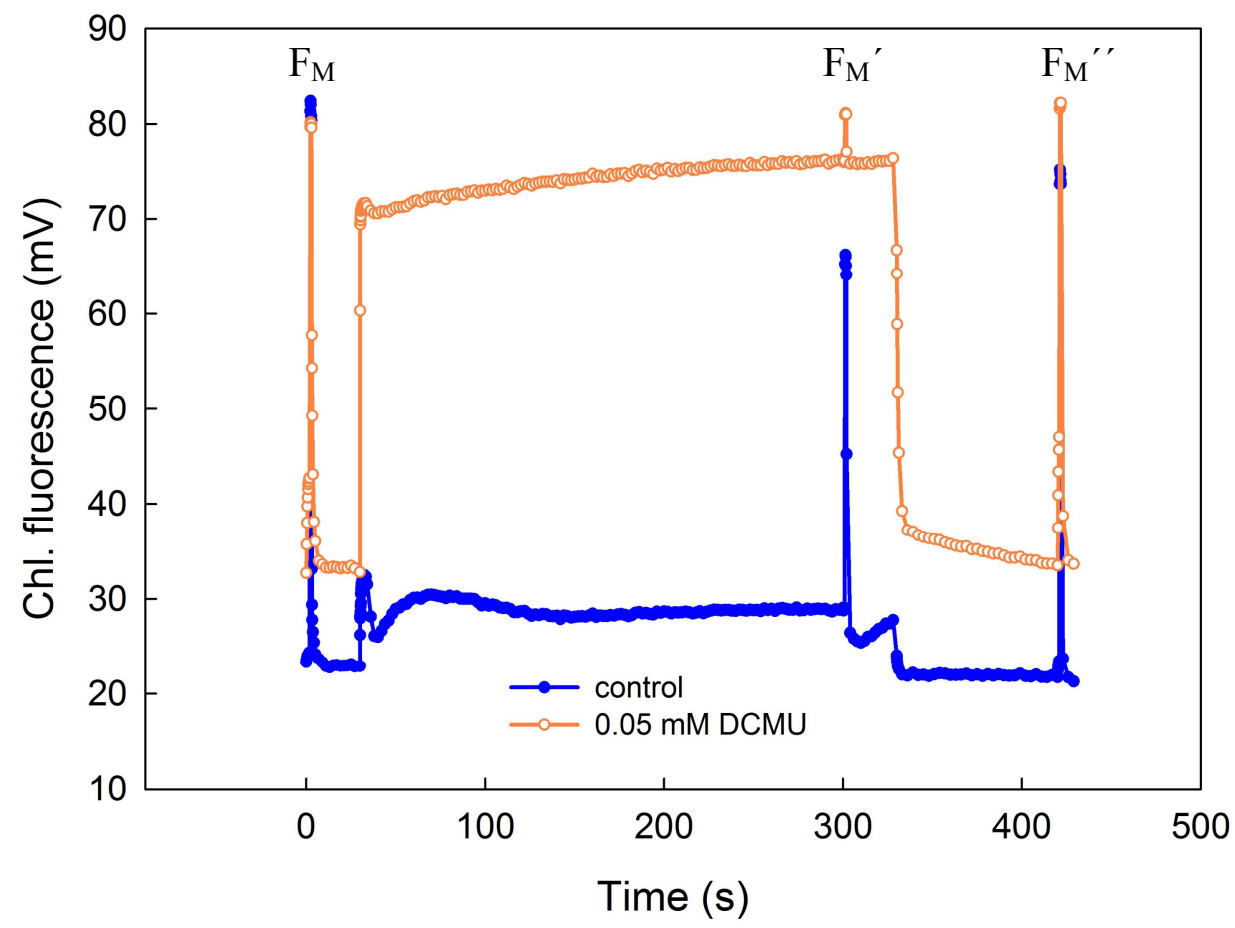

Fig. 4. Effect of DCMU addition on the shape of slow chlorophyll fluorescence kinetics. $F_{P}, F_{S}$ and a positive $\mathrm{F}_{\mathrm{M}}{ }^{\prime}$ indicate that reaction centres of PS II are not blocked completely and DCMUtreated Zygnema sp. (EEL201 strain) is still capable to perform limited primary photochemical processes of photosynthesis. 


\section{Methyl viologen effect}

Compared to untreated control, application of methyl viologen (MV) led to a decrease in $\mathrm{F}_{\mathrm{V}} / \mathrm{F}_{\mathrm{M}}$ and $\Phi_{\mathrm{PSII}}$ (see Fig. 5). The extent of the decrease, however, was much smaller than in nigericine. Nonphotochemical quenching increased by the factor of three immediatelly after MV application and then decrease slowly with time. After $2 \mathrm{~h}$ of exposition to MV, NPQ was still substantially higher than in control indicating that PS II was still under stress and protective non-photochemical processes were necessary. Such behavior can be supported by the study made on barley (Kotabová et al. 2008) that reports $10 \mu \mathrm{mol} \mathrm{MV}$-induced increase in NPQ that was attributed to violaxanthin to zeaxanthin conversion. Antioxidative response of chloroplastic photosynthetic apparatus to $\mathrm{MV}$ is, however, a complex matter since both inhibition and no change in antioxidative enzymes activity is reported (Kotabová et al. 2008). Similarly to NPQ, $\mathrm{qF}_{0}$ showed increased values in MVtreated Zygnema than in control.

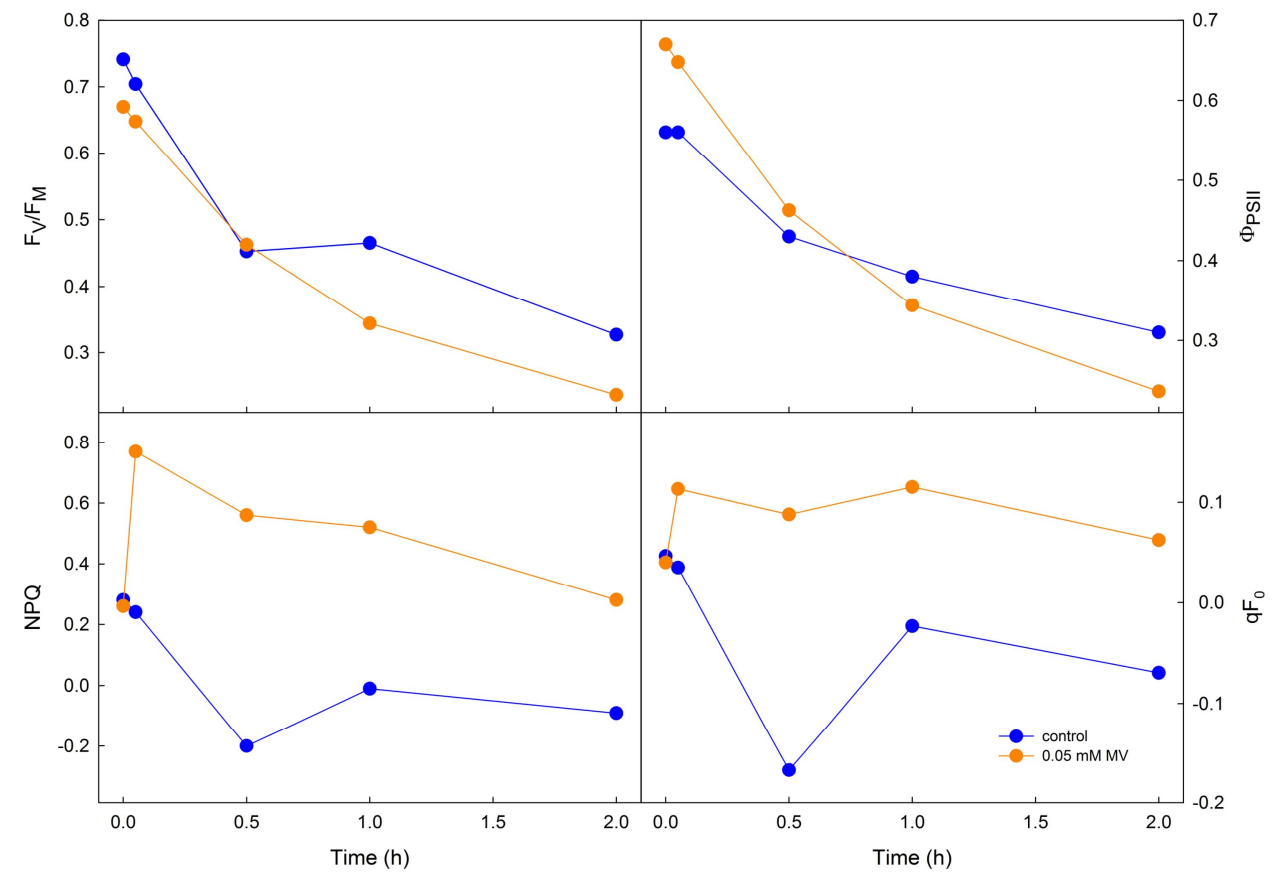

Fig. 5. Effects of methyl viologen (MV) on chlorophyll fluorescence parameters in Zygnema sp. (EEL201 strain). 


\section{Nigericine effects}

Aplication of nigericine ( 5 min in dark) led to a decrease in $\mathrm{F}_{\mathrm{V}} / \mathrm{F}_{\mathrm{M}}$ and $\Phi_{\mathrm{PSII}}$, which is demonstrated as a decrease of initial values $($ Time $=0 \mathrm{~h}$ ) in Fig. 6 . When exposed to light, nigericin-treated samples showed more or less no change in $F_{V} / F_{M}$ but a decrease followed by later increase in $\Phi_{\text {PSII }}$. Therefore, partial recovery of $\Phi_{\text {PSII }}$ was apparent. Non-photochemical quenching showed increase and then decrease, which was somewhat different from what was expected since application of nigericine leads to a strong inhibition of nonphotochemical quenching in many species (see e.g. Endo et Asada 1996, Kaňa et al. 2012), mainly energy-dependent quench- ing, delta $\mathrm{pH}$-dependent activation of deepoxidases involved into xanthophyll cycle (Cruz et al. 2011). Nigericin decreases $\Delta \mathrm{pH}$ gradient by antiporting $\mathrm{H}^{+}$at the expense of $\mathrm{K}^{+}$across membranes, resulting in the collapse qE. As a result of a breakdown in the $\mathrm{pH}$ gradient, the addition of nigericin to illuminated samples, results in an increase in $\mathrm{F}_{\mathrm{M}}{ }^{\prime}$ and strong inhibition of NPQ with a concomitant large increase in steady state fluorescence $F_{t}$. The typical concentration range for nigericin is $1-5$ mM (Falkowski et Raven 2007). Our results, however, thanks to much lower concentration do not support nigericin-induced inhibition of NPQ.

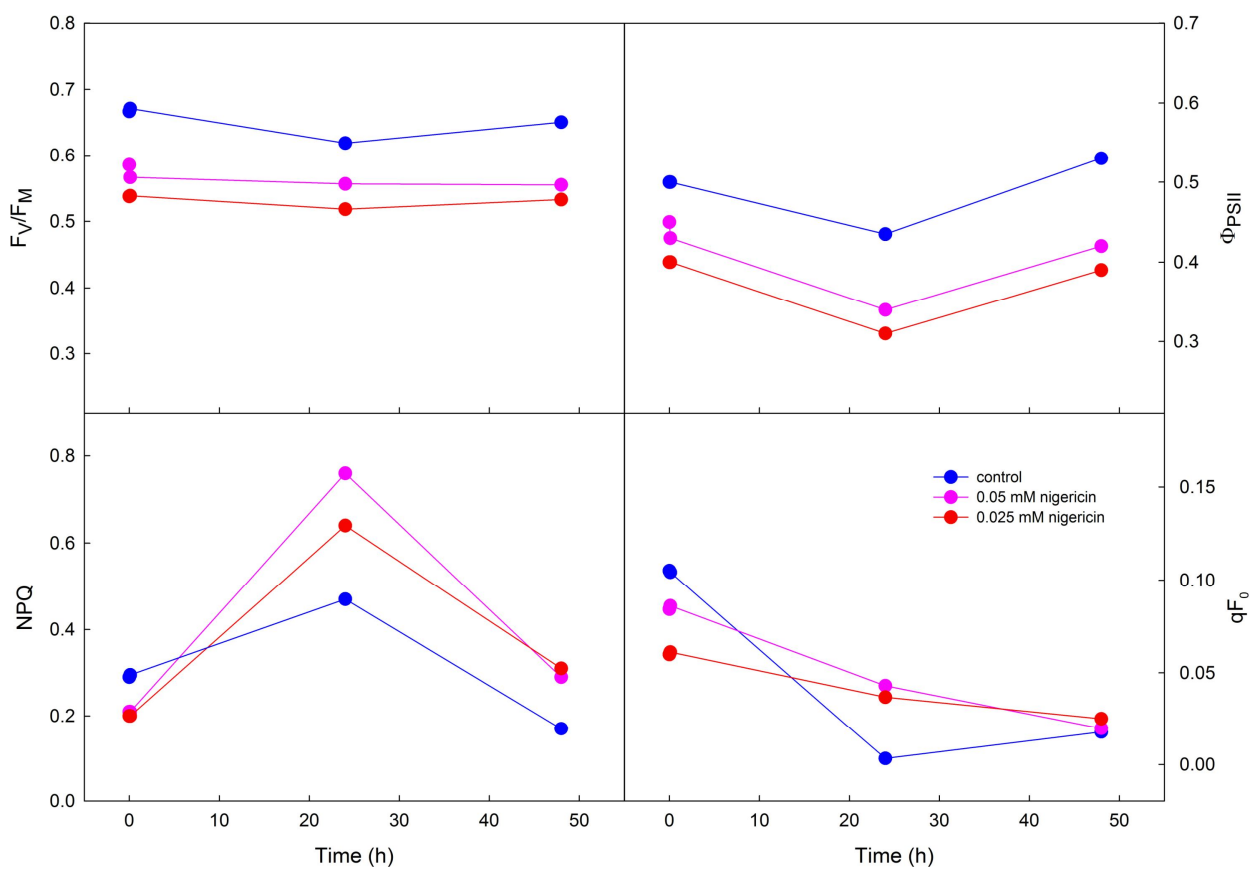

Fig. 6. Effects of nigericine on chlorophyll fluorescence parameters in Zygnema sp. (EEL201 strain). 


\section{Oxidative stress}

Addition of $\mathrm{H}_{2} \mathrm{O}_{2}$ led to a dose-dependent effect on thylakoidal photosynthetic apparatus. While control showed a decrease in $\mathrm{F}_{\mathrm{V}} / \mathrm{F}_{\mathrm{M}}$ immediately after an experiment started followed by an slight increase later. $\mathrm{H}_{2} \mathrm{O}_{2}$ addition led to an exponential $\mathrm{F}_{\mathrm{V}} / \mathrm{F}_{\mathrm{M}}$ decrease to a minimum found after $6 \mathrm{~h}$. While negative changes in PS II caused by small $\mathrm{H}_{2} \mathrm{O}_{2}$ doses (see Fig. 7) led to only a partial inactivation of PS II (minimum value of $\mathrm{F}_{\mathrm{V}} / \mathrm{F}_{\mathrm{M}}$ about
$0.35)$, the higher concentration caused almost full PS II inactivation $\left(\mathrm{F}_{\mathrm{V}} / \mathrm{F}_{\mathrm{M}}=0.15\right.$, $\left.\Phi_{\text {PSII }}=0.12\right)$. Effective quantum yield of photosynthetic processes in PS II ( $\Phi_{\text {PSII }}$ ) responded in similar way. Addition of $\mathrm{H}_{2} \mathrm{O}_{2}$ caused an exponential decrease in $\Phi_{\text {PSII }}$ lasting for $6 \mathrm{~h}$ after $\mathrm{H}_{2} \mathrm{O}_{2}$ addition followed by a slight increase. The higher concentration led to a more pronounced $\Phi_{\text {PSII }}$ decrease.

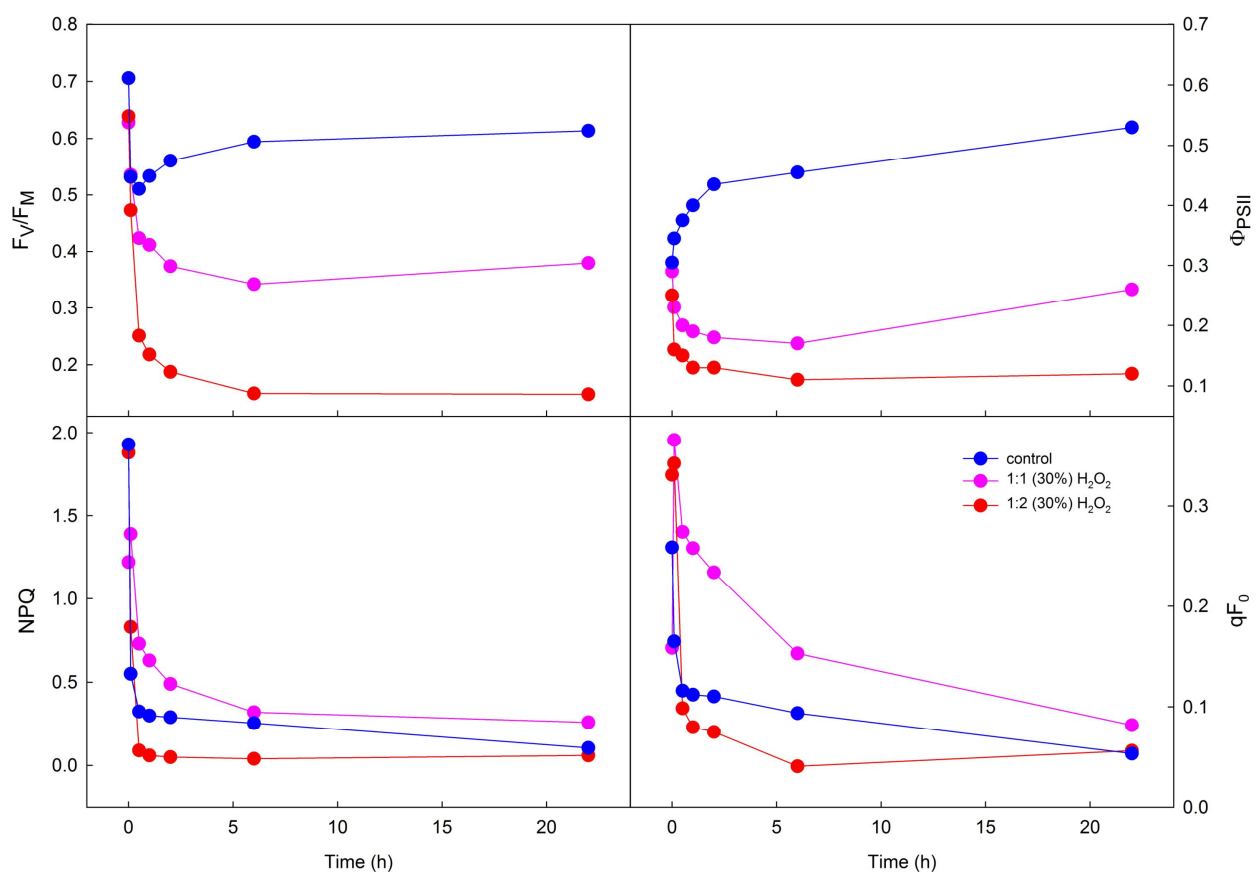

Fig. 7. Effects of oxidative stress caused by $\mathrm{H}_{2} \mathrm{O}_{2}$ on chlorophyll fluorescence parameters in Zygnema sp. (EEL201 strain).

\section{References}

Antal, T. K., Osipov, V., Matorin, D. N. and Rubin, A.B. (2011): Membrane potential is involved in regulation of photosynthetic reactions in the marine diatom Thalassiosira weissflogii. Journal of Photochemistry and Photobiology B: Biology, 102: 169-173.

Bukhov, N. G., Egorova, E. A., Govindacharya, S. and Carpentier, R. (2004): Changes in polyphasic chlorophyll a fluorescence induction curve upon inhibition of donor or acceptor side 
of photosystem II in isolated thylakoids. Biochimica et Biophysica Acta (BBA) - Bioenergetics, 1657: 121-130.

Conti, S., Hazdrová, J., HÁjek, J., Očenášová, P., Barták, M., SkÁcelová, K. and Adamo, P. (2014): Comparative analysis of heterogeneity of primary photosynthetic processes within fruticose lichen thalli: Preliminary study of interspecific differences. Czech Polar Reports, 4: 149-157.

Cornic, G., Bukhov, N.G., Wiese, C., Bligny, R. and Heber, U. (2000): Flexible coupling between light-dependent electron and vectorial proton transport in illuminated leaves of $\mathrm{C} 3$ plants; role of photosystem I-dependent proton pumping. Planta, 210: 468-477.

Cruz, S., Goss, R., Wilhelm, Ch., Leegood, R., Horton, P. and Jakob, T. (2011): Impact of chlororespiration on non-photochemical quenching of chlorophyll fluorescence and on the regulation of the diadinoxanthin cyclein the diatom Thalassiosira pseudonana. Journal of Experimental Botany, 62: 509-519.

DAll'Osto, L., CAFFarRI, S. and BAssi, R. (2005): A mechanism of nonphotochemical energy dissipation, independent from PsbS, revealed by a conformational change in the antenna protein CP26. The Plant Cell, 17: 1217-1232.

Ducruet, J. M., Gaillardon, P. and Vienot, J. (1984): Use of chlorophyll fluorescence induction kinetics to study translocation and detoxication of DCMU-type herbicides in plant leaves. Zeitschrift für Naturforschung, 39 c: 354-358.

ENDO, T., AsADA, K. (1996): Dark induction of the non-photochemical quenching of chlorophyll fluorescence by acetate in Chlamydomonas reinhardtii. Plant and Cell Physiology, 37: 551555.

Essemine, J., Govindachary, S., Joly, D., Ammar, S., Bouzid, S. and Carpentier, R. (2012): Effect of moderate and high light on photosystem II function in Arabidopsis thaliana depleted in digalactosyl-diacylglycerol. Biochimica et Biophysica Acta (BBA) - Bioenergetics, 1817: 1367-1373.

FALKOWSKI, P. G., RAVEN, J. A. (2007) :Aquatic photosynthesis, 2nd, edition. Princeton University Press, Princeton, $484 \mathrm{p}$.

FAN, DA-Y., JiA, H., BARBER, J. and ChOW, W. S. (2009): Novel effects of methyl viologen on photosystem II function in spinach leaves. European Biophysics Journal, 39: 191-199.

FERnÁNDEZ-MARÍN, B., BeCERRIL, J. M. and GARCíA-PlazAOLA, J. I. (2010): Unravelling the roles of desiccation-induced xanthophyll cycle activity in darkness: a case study in Lobaria pulmonaria. Planta, 231: 1335-1342.

FulleR, CH. L. (2013): Examining morphological and physiological changes in Zygnema irregulare during a desiccation and recovery period. Master Thesis, California State University, San Marcos, California, USA, $73 \mathrm{p}$.

HAwES, I. (1989): Filamentous green algae in freshwater streams on Signy Island, Antarctica. Hydrobiologia, 172: 1-18.

Herburger, K., Lewis, L.A. and Holzinger, A. (2015): Photosynthetic efficiency, desiccation tolerance and ultrastructure in two phylogenetically distinct strains of alpine Zygnema sp. (Zygnematophyceae, Streptophyta): role of pre-akinete formation. Protoplasma, 252: 571-589.

Holzinger, A., RoledA, M. and LüTZ, C. (2009): The vegetative arctic green alga Zygnema is insensitive to experimental UV exposure. Micron, 40: 831-838.

Iriel, A., Novo, J.M., Cordon, G.B. and Lagorio, M.G. (2014): Atrazine and methyl viologen effects on chlorophyll-a fluorescence revisited-implications in photosystems emission and ecotoxicity assessment. Photochemistry and Photobiology, 90: 107-112.

Joliot, P., JohNSON, G. N. (2011): Regulation of cyclic and linear electron flow in higher plants. PNAS, 108: 13317-13322.

Kaña, R., KotabovÁ, E., SobotKa, R. and PRÁšil, O. (2012) : Non-photochemical quenching in Cryptophyte alga Rhodomonas salina is located in chlorophyll a/c antennae. PLoS ONE, http://dx.doi.org/10.1371/journal.pone.0029700.

Kolmakov, V.I., Anishchenko, O.V., Ivanova, E.A., Gladyshev, M.I. and Sushchik, N.N. (2008): Estimation of periphytic microalgae gross primary production with DCMU- 
CH. KAKKOU et al.

fluorescence method in Yenisei River (Siberia, Russia). Journal of Applied Phycology, 20: 289-297.

Kotabová, E., Kaña, R., Kyseláková, H., Lípová, L. , Novák, O. and Ilík, P. (2008): A pronounced light-induced zeaxanthin formation accompanied by an unusually slight increase in non-photochemical quenching: A study with barley leaves treated with methyl viologen at moderate light. Journal of Plant Physiology, 165: 1563-1571.

LAVERGNE, J. (1982): Mode of action of 3-(3,4-dichlorophenyl)-1,1-dimethylurea. Evidence that the inhibitor competes with plastoquinone for binding to a common site on the acceptor side of Photosystem II. Biochimica et Biophysica Acta (BBA) - Bioenergetics, 682: 345-353.

MyiaKe, СH., YokоtA, A. (2001): Cyclic flow of electrons within PSII in thylakoid membranes. Plant and Cell Physiology, $42: 508-515$.

Nishio, J. N., Whitmarsh, J. (1993): Dissipation of the proton electrochemical potential in intact chloroplasts (II. The $\mathrm{pH}$ gradient monitored by cytochrome $\mathrm{f}$ reduction kinetics). Plant Physiology, 101: 89-96.

PichrtovÁ, M., Remias, D., Lewis, L. A. and Holzinger, A. (2013): Changes in phenolic compounds and cellular ultrastructure of Arctic and Antarctic strains of Zygnema (Zygnematophyceae, Streptophyta) after exposure to experimentally enhanced UV to PAR ratio. Microbial Ecology, 65:6-83.

PichrtovÁ, M., KulichovÁ, J. and Holzinger, A. (2014): Nitrogen limitation and slow drying induce desiccation tolerance in conjugating green algae (Zygnematophyceae, Streptophyta) from Polar Habitats. Plos One, Volume 9 | Issue $11 \mid$ e 113137.

ROHÁČEK, K., SOUKupovÁ, J. and BARTÁK, M. (2008): Chlorophyll fluorescence: A wonderfool tool to study plant physiology and plant stress. In: B. Schoefs (ed.): Plant Cell Compartments Selected Topics. Research Signpost, Kerala, India, pp. 41-104.

Schansker, G., Tóth, S. Z. and Strasser, R. J. (2005): Methylviologen and dibromothymoquinone treatments of pea leaves reveal the role of photosystem I in the Chl a fluorescence rise OJIP. Biochimica et Biophysica Acta, 1706: 250-261.

Simis, S. G., Huot, Y., Babin, M., Seppälä, J. and MetsamaA, L. (2012): Optimization of variable fluorescence measurements of phytoplankton communities with cyanobacteria. Photosynthesis Research, 112: 13-30.

VAVILIN, D.V., TYYSTJÄRVI, E.and ARO, E.-M. (1998): Model for the fluorescence induction curve of photoinhibited thylakoids. Biophysical Journal, 75: 503-512.

Vilumbrales, D.M., SkÁcelovÁ, K. and BARTÁK, M. (2013): Sensitivity of Antarctic freshwater algae to salt stress assessed by fast chlorophyll fluorescence transient. Czech Polar Reports, 3 : 163-172.

Volgusheva, A. A., Zagidullin, V. E., Antal, T.K., Korvatovsky, B.N., Krendeleva, T. E. PAschenko, V. Z. and RuBin, A. B. (2007): Examination of chlorophyll fluorescence decay kinetics in sulfur deprived algae Chlamydomonas reinhardtii. Biochimica et Biophysica Acta (BBA) - Bioenergetics, 1767: 559-564.

VREDENBERG, W. (2015): A simple routine for quantitative analysis of light and dark kinetics of photochemical and non-photochemical quenching of chlorophyll fluorescence in intact leaves. Photosynthesis Research, 124: 87-106. 